\title{
Rocket seed (Eruca sativa Mill) gum: physicochemical and comprehensive rheological characterization
}

\author{
Gözde KUTLU ${ }^{1}$ (D), Alican AKCICEK ${ }^{1}$ (D), Fatih BOZKURT¹ (D), Salih KARASU ${ }^{1}$ (D), \\ Zeynep Hazal TEKIN-CAKMAK ${ }^{1 \star}$ (I)
}

\begin{abstract}
This study aimed to determine the physicochemical and rheological characterization of Rocket seed gum (RSG) as a plant-based natural gum. Moisture, ash, protein, monosaccharide composition, and $\mathrm{pH}$ value were determined. Mannose and galactose were the main monosaccharides with a ratio of (mannose/galactose) 1.52 . The absorptions at wavenumber $2855 \mathrm{~cm}^{-1}$ and $2922 \mathrm{~cm}^{-1}$ indicate the presence of galactose and arabinose. RSG showed shear-thinning flow behavior at all concentrations. The K value of the RSG ranged between 0.24 and 6.31 Pa.s ${ }^{\mathrm{n}}$ and significantly increased with increased gum concentration. Hysteresis area was found 11.53-183.23 and increased with increasing gum concentration. The percentage recovery for the $\mathrm{G}^{\prime}$ was significantly affected by gum concentrations and found as 42.54-81.20. RSG showed a solid-like structure, the storage modulus $\left(G^{\prime}\right)$ was higher than the loss modulus $\left(G^{\prime \prime}\right)$ in all frequency range. $G^{\prime}$ and $G^{\prime \prime}$ value increased with increased RSG concentration. The physicochemical and rheological characterization indicated that RSG could be evaluated as thickeners and gelling agents in the food industry.
\end{abstract}

Keywords: rocket seed gum; sugar composition; rheology; FT-IR.

Practical Application: Evaluation of RSG as a novel plant-based natural gum.

\section{Introduction}

Gums are complex polysaccharides with high molecular weight and lots of hydrophilic groups that dissolve in water providing viscosity to aqueous systems (Dabestani et al., 2018). Starch and its derivatives, galactomannans, carrageenans, pectin, gum arabic, and cellulose are mostly preferable gums that are used as a thickening and gelling agent, texture modifier, emulsifiers, and stabilizers in the food industry (Wang et al., 2019). Besides, new plant-based gum obtained from different seeds such as flaxseed, white mustard seed, yellow mustard seed, fenugreek seed, sage seed, and cress seed has been introduced by researchers in the last years (Balke \& Diosady, 2000; Brummer et al., 2003; Cui et al., 1993; Cui et al., 1994; Karazhiyan et al., 2009). Knowledge of the physicochemical, functional, and rheological properties of a new gum source is useful for the evaluation of gum's behavior in a large number of food products and their processing (Koocheki \& Razavi, 2009). Many studies have been conducted on the rheological properties of seed gum solutions such as fenugreek seed gum, basil seed gum, and locust bean seed gum (Dakia et al., 2008; Farahmandfar et al., 2019; Gadkari et al., 2018). Polysaccharides, the main components of natural gums, consist of more than one type of monosaccharide (Dickinson, 2003). The difference in the monosaccharide compositions of gums affects the rheological properties and solubility of gums. Therefore, the monosaccharide compositions should be determined in the evaluation of rheological properties and solubility.
Eruca sativa ('rocket' in English) is a lifelong herb of the family Brassicaceae grown in Southern Europe and India. For many years, rocket plants have been used as a food ingredient, especially in a salad. Rocket plants contain a wide range of health-promoting phytochemical compounds such as polyphenols, fibers, and glucosinolates (Koubaa et al., 2016; Miyazawa et al., 2002; Perry \& Metzger, 1980). The seeds of rocket plants have been used for oil production in the industry because of their high oil contents $(20.0 \%)$ and Erucic acid contents, one of the most sought-after fatty acids (Koubaa et al., 2016). Also, the rocket seed has a significant amount of total carbohydrate (23.1\%), crude fibers (20.4\%), and crude protein (31.0\%)-rich (Nail et al., 2017). Thanks to their chemical composition, rocket seeds may have reasonable gum content with functional properties. The effect of extraction parameters on some technological properties and extraction yield of Eruca sativa seed mucilage was studied (Koocheki et al., 2011). However, there is no published study on the comprehensive rheological characterization of RSG.

In this study, the extraction procedure of RSG extracted from Eruca sativa seed and the physicochemical and rheological properties of RSG were investigated. This characterization gives potential applications of RSG in the food industry as a natural food gum. Also, the rheological properties of RSG are important to improve the functional properties of food. 


\section{Material and method}

Rocket seeds (Eruca Sativa Mill.) were obtained from the local producers. All chemicals used for extraction and purification were analytical grade obtained from Merck (Darmstadt, Germany).

The study consist of two parts which were the extraction of RSG and the characterization of RSG's physicochemical (moisture, ash, and protein content, sugar composition) and rheological properties (the steady shear, dynamic rheological properties, 3-ITT, and creep recovery test) of RSG dispersions (0.2-1.0\%). This study was investigated to get information about gum characteristics and stability.

\subsection{RSG Extraction}

The Rocket seed gum was extracted with distilled water (water:seed of 20:1) in a magnetic heating stirrer at $80 \pm 1.0^{\circ} \mathrm{C}$ for 2 hours. Rocket seeds swell by taking the water, and the gel structures are out of the granules. The solution obtained as a result of the extraction was added to water to $5000 \mathrm{~mL}$. The solution was diluted. Rocket seeds, which settle towards the bottom with dilution, were taken from the solution by filtration. For the removal of water from the structure, the separated solution was concentrated by evaporating in the evaporator at $80^{\circ} \mathrm{C}$ for 3 hours, and dilution was made by adding ethyl alcohol (96\%) in the ratio of $1: 2(\mathrm{~h}: \mathrm{h})$ to the solution. With the addition of alcohol, the gum in the solution increased upwards due to the density difference and was collected on the surface. The collected gums were taken from the surface in a container and then left in the oven at $50{ }^{\circ} \mathrm{C}$ for 1 day to dry. After the drying process, RSG was milled and sieved using a mesh 18 sifter.

\subsection{Physicochemical properties of RSG}

Moisture, ash, and protein content of the RSG were analyzed according to AOAC Official Methods (Baur \& Ensminger, 1977). Determination of sugar composition of the samples was performed using the HPLC system (Shimadzu, Japan), equipped with a refractive index detector (RID-10A) and CARBOSep CHO-682 Pb column. The column temperature was thermostatted at $80{ }^{\circ} \mathrm{C}$. The chromatographic separation was obtained using the isocratic flow of ultrapure water at a flow rate of $0.4 \mathrm{ml} / \mathrm{min}$. For each analysis, 10 grams of sample was extracted with the addition of $100 \mathrm{~mL}$ of distilled water for 4 hours using a mechanic shaker at room temperature. After that, the extract was filtered through a $0.45 \mu \mathrm{m}$ membrane filter, and $20 \mu \mathrm{L}$ filtrate was injected into the column. The number of sugars was calculated using an external calibration curve, and the results were expressed as a $\mathrm{g} / 100 \mathrm{~g}$ sample.

A Bruker Tensor 27 spectrometer (Bremen-Germany) equipped with an ATR accessory with a diamond crystal module was used for obtaining the resistance mechanism by Fourier transform infrared (FT-IR) spectra of RSG. OPUS program Version 7.2 for Windows from Bruker Gmbh was used for instrument control and data acquisition. Wavelength ranged from 3800 to $600 \mathrm{~cm}^{-1}$ at $4 \mathrm{~cm}^{-1}$ resolution accumulating 16 scans per spectra was used for the FT-IR spectra. The background air spectrum subtracted all sample spectra (Singthong et al., 2005).

\subsection{Rheological Analyzes of RSG}

Gum solutions were prepared by dissolving RSG and its different concentrations $(0.2-1.0 \% \mathrm{w} / \mathrm{v})$ in distilled water at $25^{\circ} \mathrm{C}$ and keeping overnight on a mixer to complete hydration.

Stress or strain-controlled and temperature-controlled oscillatory rheometer (Anton Paar, MCR 302, Australia) was used to determine rheological properties of the RSG solutions. The steady shear properties and time-dependent flow behavior, dynamic shear properties, 3-ITT rheological properties, and creep recovery test were performed.

\subsection{Steady shear properties and hysteresis area}

Steady shear properties of RSG solutions were determined in the shear rate range of $0-100(1 / \mathrm{s})$ at $25^{\circ} \mathrm{C}$ by using a parallel plate configuration (diameter $50 \mathrm{~mm}$, gap $0.5 \mathrm{~mm}$ ). The RSG solutions (approximately $2 \mathrm{~g}$ ) were placed in the rheometer plate, and the analysis was carried out after reaching the desired temperature. Each concentration of RSG samples was repeated three times. The shear stress values of RSG solutions were determined as a function of the shear rate. The relation between the shear rate and shear stress was calculated using the Ostwald de Waale model and non-linear regression.

$\tau=K \gamma^{n}$

In Equation 1, $\tau$ shows shear stress $(\mathrm{Pa}), \mathrm{K}$ consistency index, $\gamma$ shear rate $(1 / \mathrm{s})$, and $\mathrm{n}$ the flow behavior index.

The thixotropic properties of RSG were determined by using hysteresis, which was composed of two steps (upward curve and downward curve). Hysteresis area was characterized by increasing shear rate range from $0.01 \mathrm{~s}^{-1}$ to $100 \mathrm{~s}^{-1}$ in $5 \mathrm{~min}$ and then to measure the downward curve by reversing shear rate range from $100 \mathrm{~s}^{-1}$ to $0.01 \mathrm{~s}^{-1}$ in $5 \mathrm{~min}$ at $25^{\circ} \mathrm{C}$.

\subsection{Three-Time Interval Thixotropic Test (3-ITT)}

3-ITT three interval thixotropic test is composed of three stages. In the first time interval, RSG is analyzed at low shear rates $(0.51 / \mathrm{s})$. In the second time interval, RSG is deformed by a high shear rate $(150 \mathrm{l} / \mathrm{s})$ to characterize the deformation of RSG. In the third time interval, which is the same condition first time interval, analyses were performed in low shear rates. Thus, the time of recovery and quantity can be determined (Toker et al., 2015).

$\mathrm{G}_{\mathrm{i}}$ (at the initial state of the product) $\mathrm{G}_{0}$ (after deformation applied $G^{\prime}$ value) and $G_{e}$ (after recovery of sample $G^{\prime}$ value) values are characterized by deformation equation (Equation 2) (Toker et al., 2015):

$\%$ Deformation $=\left(\frac{\left(G_{3}-G_{0}\right)}{G_{3}}\right) \times 100$

The recovery degree of RSG was determined by the following equation (Equation 3), 
$\%$ Recovery $=\left(\frac{G_{e}}{G_{3}}\right) \times 100$

Firstly the linear viscoelastic region was determined with the amplitude sweep test. Then, the constant and variable shear rate was selected for the 3-ITT. 3-ITT rheological properties of RSG were determined by constant shear rate and variable shear rate. In the first interval, the constant shear rate was applied to the RSG. Then in the second time interval, the variable shear rate was applied on RSG. In the third time interval, which is the same first time interval, the constant shear rate applied on the RSG to determined dynamic rheological properties of RSG in the second time interval. For this reason, the 3-ITT test gives information about changing the solid structure of RSG with time. For the interpretation of the data which is obtained as a result of the 3-ITT test, the terms related to recovery should be obtained. For this purpose, the second-order structural kinetic model was used and $G_{0}, G_{e}$, and k values were calculated. $G_{0}$ (the initial values of the storage and loss modulus), $\mathrm{G}_{e}$ (the equilibrium storage modulus), $\mathrm{k}$ (the rate constant of recovery of the sample) and also in this model $n=2$, are specified by the following Equation 4:

$\left[\frac{G^{\prime}-G_{e}}{G_{0}-G_{e}}\right]^{1-n}=(n-1) k t+1$

\section{Dynamic Shear Properties}

Dynamic shear properties were determined by parallel plate configuration. Firstly, the amplitude sweep test was applied in the $0.1-100 \%$ strain range to determine the linear viscoelastic region. Then, the frequency sweep test was performed in the linear viscoelastic region at a frequency of $0.1-10 \mathrm{~Hz}$ and in the angular velocity range of 0.1-64 (w) to record storage $\left(G^{\prime}\right)$, loss modulus $\left(G^{\prime \prime}\right)$ and complex viscosity $\left(n^{*}\right)$ values. Dynamic shear properties parameters were determined by using the Power Law model and non-linear regression (Equation 5 \& Equation 6) (Yoo \& Rao, 1996):

$$
G^{\prime}=K^{\prime}(\omega)^{n^{\prime}}
$$

$$
G^{\prime \prime}=K^{\prime}(\omega)^{n^{\prime \prime}}
$$

where $\mathrm{G}^{\prime}(\mathrm{Pa})$ is the storage modulus, $\mathrm{G}^{\prime \prime}(\mathrm{Pa})$ is the loss modulus, $\omega$ is the angular velocity value $(1 / s)$, and $K$, $K^{\prime \prime}$ consistency index values and n', n" represent the flow behavior index values.

\subsection{Statistical analysis}

The statistical analysis was carried out using the Statistica software program (StatSoft, Inc., Tulsa, OK). All the rheological analyses were conducted in triplicate. The standard deviation and mean value were shown. ANOVA was conducted to determine the differences in rheological parameters of gum solutions. Duncan, multiple comparison tests at 95\% significance level was used to determine the effect of gum concentration on rheological parameters.

\section{Results and discussion}

\subsection{Physicochemical Properties}

The chemical compositions of RSG were presented in Table 1. Carbohydrate, protein, moisture, and ash content of RSG were $80.38 \%, 5.81 \%, 10.26 \%$, and 3.55\%, respectively. Koocheki et al. (2012) reported that rocket seed mucilage contains $67.97 \%$ carbohydrate, $9.75 \%$ protein, $12.28 \%$ moisture, $10 \%$ ash, and no fat content. The pH value of RSG was determined as 5.71. Table 1 also indicates the sugar composition of the RSG.

RSG has high carbohydrate (80.38\%) and low protein (5.81\%) contents so that the purification method used when obtaining gum could be appropriate. While the carbohydrate content of RSG (80.38\%) was higher than that of guar gum $(71.1 \%)$, it was close to that of Descurainia sophia seed gum (78.23\%) and less than that of Soymida febrifuga exudate gum $(88.77 \%)$ (Bhushette \& Annapure, 2018; Busch et al., 2015; Hamidabadi Sherahi et al., 2017). The protein content of gum is a crucial parameter determining its emulsion, foaming, and filmforming capacity. RSG has higher protein content, some other natural gums reported from previously published studies by Bhushette \& Annapure (2018) and Hamidabadi Sherahi et al. (2017). When comparing commercial gums, the protein content of RSG was higher than that of xanthan gum (2.125\%), lower than that of guar gum (8.19\%), and close to that of locust bean gum (5.2-7.4\%) (Hamidabadi Sherahi et al., 2017).

When considering the monosaccharide composition, RSG has a high level of mannose and galactose. The RSG mannose/galactose ratio was found as 1.52 , indicating that galactose's substitution level in gum polymers was very high. In comparison, the mannose/galactose ratio of RSG is less than that of Descurainia sophia seed gum (1.62) and higher than that of fenugreek seed gum (1.1) (Brummer et al., 2003; Hamidabadi Sherahi et al., 2017). The higher level of galactose substitution means higher solubility in water.

The FTIR spectrum is generally used to identify organic functional groups in the polysaccharide structure. FTIR spectra of 1\% RSG solution was shown in Figure 1. Figure 1 demonstrated all typical bonds and peaks characteristic of the polysaccharide. The peaks between $800 \mathrm{~cm}^{-1}$ and $1200 \mathrm{~cm}^{-1}$ showed the highly entangled C-C-O, C-OH, C-O-C stretching modes of polymers structure, and this area was called the "fingerprint" area for carbohydrates (Kačuráková et al., 1998; Razavi et al., 2014). As it can be seen in Figure 1, the band in this range was $1018 \mathrm{~cm}^{-1}$ which represented alkene $\mathrm{C}-\mathrm{H}$ bend from polysaccharides for

Table 1. The chemical composition of the RSG.

\begin{tabular}{crlr}
\hline \multicolumn{2}{c}{ Seed Composition $(\mathrm{w} / \mathrm{w} \%)$} & \multicolumn{3}{c}{ Sugar composition $(\mathrm{w} / \mathrm{w} \%)$} \\
\hline Carbohydrate & $80.38 \pm 1.13$ & Galactose & $24.49 \pm 0.74$ \\
Protein & $5.81 \pm 0.26$ & Mannose & $37.29 \pm 0.32$ \\
Moisture & $10.26 \pm 0.19$ & Glucose & $9.89 \pm 0.05$ \\
Ash & $3.55 \pm 0.04$ & Fructose & $11.59 \pm 0.11$ \\
& & Arabinose & $13.28 \pm 0.23$ \\
\hline
\end{tabular}

\footnotetext{
${ }^{\star}$ Values are means \pm SD of triplicate determination.
} 


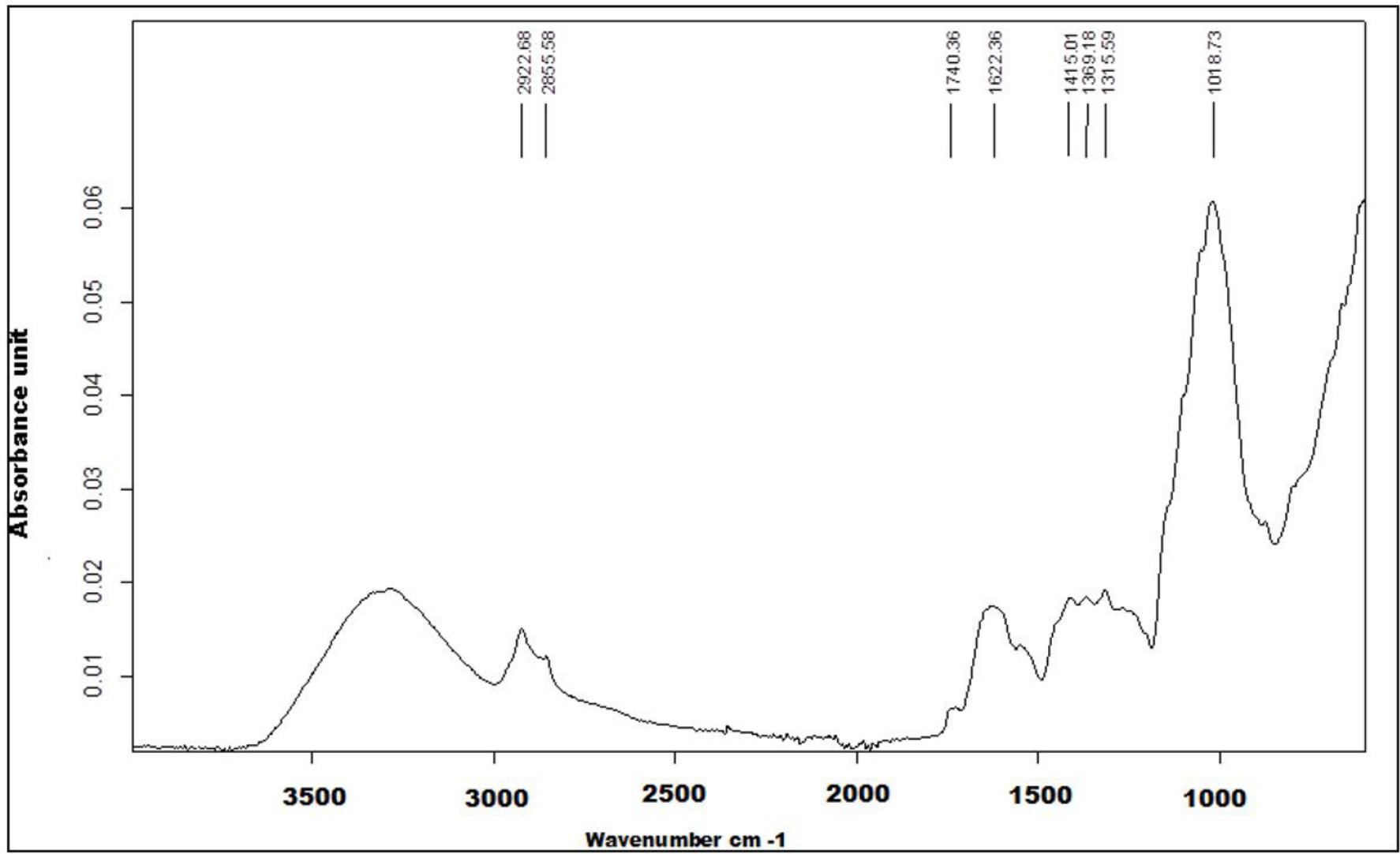

Figure 1. FT-IR spectra 1\% RSG solution.

the gums (Daoub et al., 2018). The range between $1200 \mathrm{~cm}^{-1}$ and $1500 \mathrm{~cm}^{-1}$ attributed to the coupling of the deformation vibrations of groups consisting of hydrogen atoms, namely $\mathrm{CCH}, \mathrm{HCH}, \mathrm{COH}$, and HCO (Hamidabadi Sherahi et al., 2017). These bands in this range were $1315 \mathrm{~cm}^{-1}, 1369 \mathrm{~cm}^{-1}$, and $1415 \mathrm{~cm}^{-1}$. The absorptions at wavenumber $1622 \mathrm{~cm}^{-1}$ and $1740 \mathrm{~cm}^{-1}$ resulted from C-OO groups and valence vibration. The peaks which were shown in the $2800-3000 \mathrm{~cm}^{-1}$ wavenumber range was represented the C-H stretching vibration of $\mathrm{CH}_{2}$ groups, symmetric and asymmetric of the free sugar. These bands in this range were $2855 \mathrm{~cm}^{-1}$ and $2922 \mathrm{~cm}^{-1}$ indicate the presence of sugars, galactose and arabinose. The area of FT-IR spectra between $3000 \mathrm{~cm}^{-1}$ and $3500 \mathrm{~cm}^{-1}$ indicated $\mathrm{O}-\mathrm{H}$ stretching modes due to the present combination of water and polymers, which involved hydrogen bonds (Kačuráková et al., 1998).

\subsection{Steady Shear Rheological Properties of the RSG}

Figure 2 shows the flow properties and viscosity of RSG solutions with different concentrations $(0.2-1.0 \% \mathrm{w} / \mathrm{v})$ over the range of shear rate from 0.01 to $100 \mathrm{~s}^{-1}$. According to Figure 2a, the samples' viscosity of RSG decreased with an increase in the shear rate at all concentrations. The increase in shear rate led to a breakdown of molecular bonds, and therefore molecules became regular and internal friction decreased. As a result, the viscosity of RSG solutions decreased (Wang et al., 2019). The decrease in viscosity by an increase in shear rate indicated a non-Newtonian shear-thinning flow behavior for RSG solutions at all concentrations (Figure 2b). The most used hydrocolloids in the food industry like locust bean gum (Dakia et al., 2008) and xanthan gum (Zhong et al., 2013) showed that shear-thinning rheological behavior.

Seed gums such as Chinese quince seed gum (Wang et al., 2019), Acacia nilotica exudate gum (Bhushette \& Annapure, 2017), Albizia zygia gum (Eddy et al., 2013), Brea plant gum (Bertuzzi et al., 2012), Acanthophyllum bracteatum root gum (Jahanbin et al., 2012), and gum Kondagogu (Vinod et al., 2008) showed shear-thinning behavior. Hydrogen bonds between molecular and atomic groups and high molecular weight are responsible for the shearthinning behavior of RSG (Fijan et al., 2007). Shear-thinning hydrocolloids are used to improve and modify food texture during high shear processing conditions like pumping and filling (Vardhanabhuti \& Ikeda, 2006). Shear-thinning rheological behavior is desired for typical gum solutions due to the polymeric matrix. High molecular weight and these properties might be one of the best factors for using gum as a food additive. RSG solutions can improve or modify the food industry's texture as a novel natural food hydrocolloid due to having shear thinning behavior (Tada et al., 1998).

Ostwald de Waale model was successfully applied for the flow behavior of RSG solutions $\left(\mathrm{R}^{2}>0.96\right)$. Consistency index $(\mathrm{K})$ and the flow behavior index $(\mathrm{n})$ value of RSG solutions were calculated by the Power Law model and presented in Table 2 . The $\mathrm{K}$ values and $\mathrm{n}$ values were found, respectively $0.24-6.31$ Pa. $\mathrm{s}^{\mathrm{n}}$ and $0.35-0.13$. The increase of RSG solution (from $0.2 \%$, $(\mathrm{w} / \mathrm{v})$ to, $1.0 \%,(\mathrm{w} / \mathrm{v})$ caused increasing $\mathrm{K}$ values and decreased 
$\mathrm{n}$ value. The $\mathrm{n}$ values at all concentrations of RSG solutions were less than 1 , indicating that showed a non-Newtonian shearthinning behavior of the nature of RSG solutions. These results demonstrated that different concentrations of RSG solutions affected the steady shear properties of RSG solutions.

The strong shear thinning character of higher RSG concentrations was explained by occurring more hydrogen bonds than the other concentration of RSG solutions (Wang et al., 2019). This result was compatible with other studies reported for natural and synthetic gums like locust bean gum (Dakia et al., 2008), xanthan gum, asafoetida gum (Saeidy et al., 2019), Chinese quince seed gum
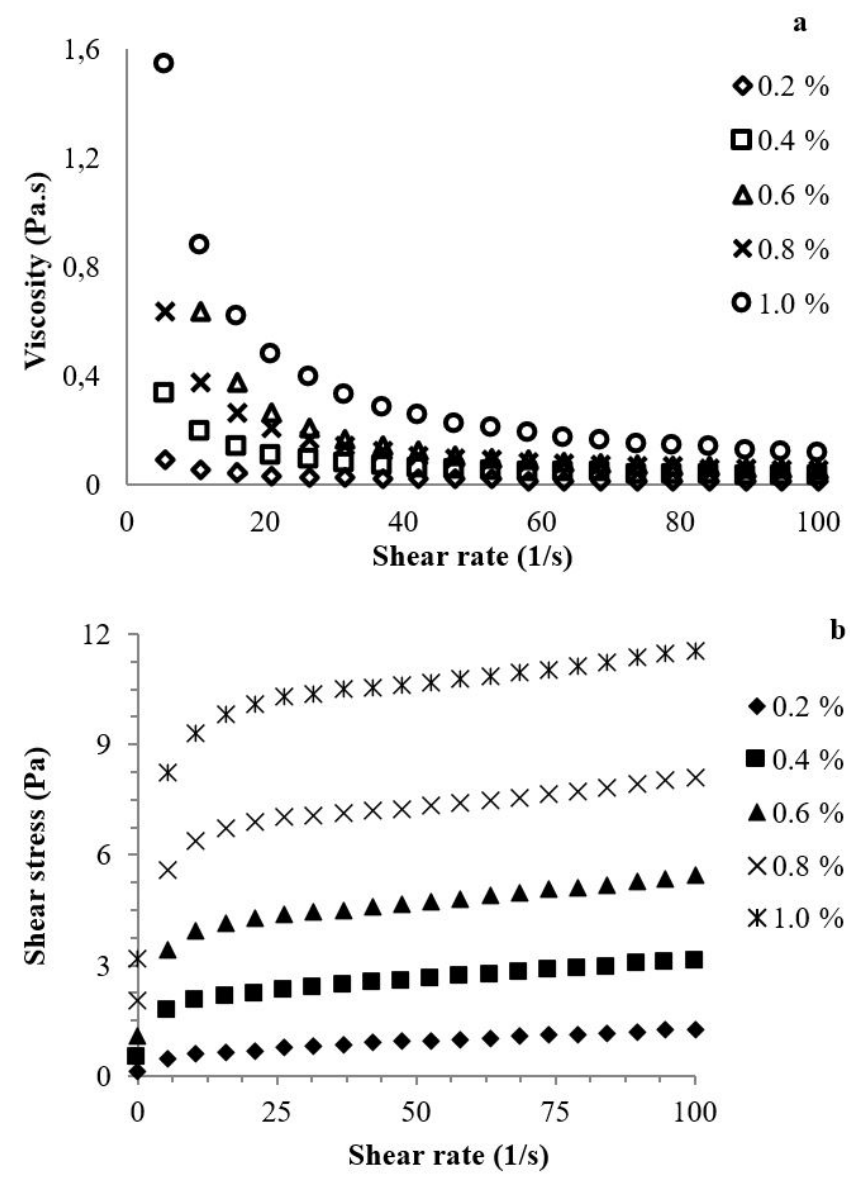

Figure 2. Flow behavior properties and viscosity versus the shear rate at different concentrations of RSG solutions. a. shear rate versus appearance viscosity, b. shear rate versus shear stress.
(Wang et al., 2019) and fenugreek gum (Gadkari et al., 2018). As we can see in Table 2, a 1\% concentration of RSG showed a higher $\mathrm{K}$ value than the other concentrations of RSG solutions due to higher solid contents, leading to increased viscosity. Higher solid contents have properties like forming film and molecular bonds (Maskan \& Gögüş, 2000). $0.2 \%$ concentration of gum solutions showed a lower $\mathrm{K}$ value due to having weak molecular interactions and low solid contents. The results indicated that the RSG solution's pseudo-plastic character was more clearly related to increasing gum concentrations. This characteristic provides important applications in the food industry, as the RSG solutions can display high viscosity and light mouthfeel in a product.

\subsection{Thixotropic behavior of RSG solution}

\section{Hysteresis area}

The thixotropic behavior of RSG solutions was shown in Figure 3, which was explained by applied increasing and decreasing the shear rate at different concentrations.

The thixotropic behavior of RSG solutions is related to the breakdown of molecular entanglements, which causes decrease shear stress and viscosity with time (Farahmandfar et al., 2019). The up curve did not overlap with the down curve. The area between the up and down curve is called the hysteresis loop, and it symbolized time-dependent fluid behavior and a wide of thixotropy (Lee et al., 2009). Hysteresis area indicated the energy needed to break down the bond at all concentrations of gum solutions (Koocheki et al., 2013). As can be seen in Table 2, hysteresis area (\%) of RSG solutions were found $10.67 \%, 13.51 \%$, $15.05 \%, 17.20 \%, 18.61 \%$, and hysteresis area (A1-A2) of the RSG found $11.53,33.23,62.11,121.42,183.23$ respectively for $0.2-1 \%$. $1 \%$ concentration of RSG solutions showed the larger hysteresis area and the stronger thixotropic properties. Besides, these concentrations showed higher structural strength due to higher occurred inter and intramolecular interactions; therefore, recovery of the RSG solutions takes a longer time (Wang et al., 2016). A similar trend was reported by (Wang et al., 2019). This result also indicated that the increase in concentrations of the sample might lead to thixotropic behavior. The lowest RSG solutions $(0.2 \%)$ displayed the weakest thixotropic behavior due to low viscosity and rheological instability. Whereas it also showed that the highest recovery of the RSG solutions, which means that after deformation, returned to its original structure quickly than the other concentrations. Similar results were obtained by (Razmkhah et al., 2016; Wang et al., 2019). When the RSG's

Table 2. Ostwald de Waele parameters and hysteresis area of RSG at a different concentration

\begin{tabular}{|c|c|c|c|c|c|}
\hline \multirow{2}{*}{$\begin{array}{c}\text { Concentration } \\
(\% \mathrm{w} / \mathrm{v})\end{array}$} & \multicolumn{3}{|c|}{ Ostwald de Waele Parameters } & \multicolumn{2}{|c|}{ Time-dependent Flow } \\
\hline & $\mathrm{K}\left(\mathrm{Pa} . \mathrm{s}^{\mathrm{n}}\right)$ & $\mathrm{n}$ & $\mathrm{R}^{2}$ & Hysteresis Area $\left(\mathrm{A}_{1}-\mathrm{A}_{2}\right)$ & Hysteresis Area (\%) \\
\hline 0.2 & $0.24 \pm 0.01^{\mathrm{e}}$ & $0.35 \pm 0.005^{\mathrm{a}}$ & 0.99 & $11.53^{\mathrm{e}}$ & $10.67^{\mathrm{e}}$ \\
\hline 0.4 & $1.16 \pm 0.09^{\mathrm{d}}$ & $0.21 \pm 0.006^{\mathrm{b}}$ & 0.99 & $33.23^{\mathrm{d}}$ & $13.51^{\mathrm{d}}$ \\
\hline 0.6 & $2.42 \pm 0.02^{\mathrm{c}}$ & $0.17 \pm 0.001^{\mathrm{c}}$ & 0.98 & $62.11^{\mathrm{c}}$ & $15.05^{\mathrm{c}}$ \\
\hline 0.8 & $4.20 \pm 0.12^{\mathrm{b}}$ & $0.14 \pm 0.001^{\mathrm{d}}$ & 0.97 & $121.42^{\mathrm{b}}$ & $17.20^{\mathrm{b}}$ \\
\hline 1.0 & $6.31 \pm 0.00^{\mathrm{a}}$ & $0.13 \pm 0.002^{\mathrm{e}}$ & 0.96 & $183.23^{\mathrm{a}}$ & $18.61^{\mathrm{a}}$ \\
\hline
\end{tabular}

${ }^{\star}$ Different letters in the same column indicate significant differences among samples $(\mathrm{P}<0.05)$. 


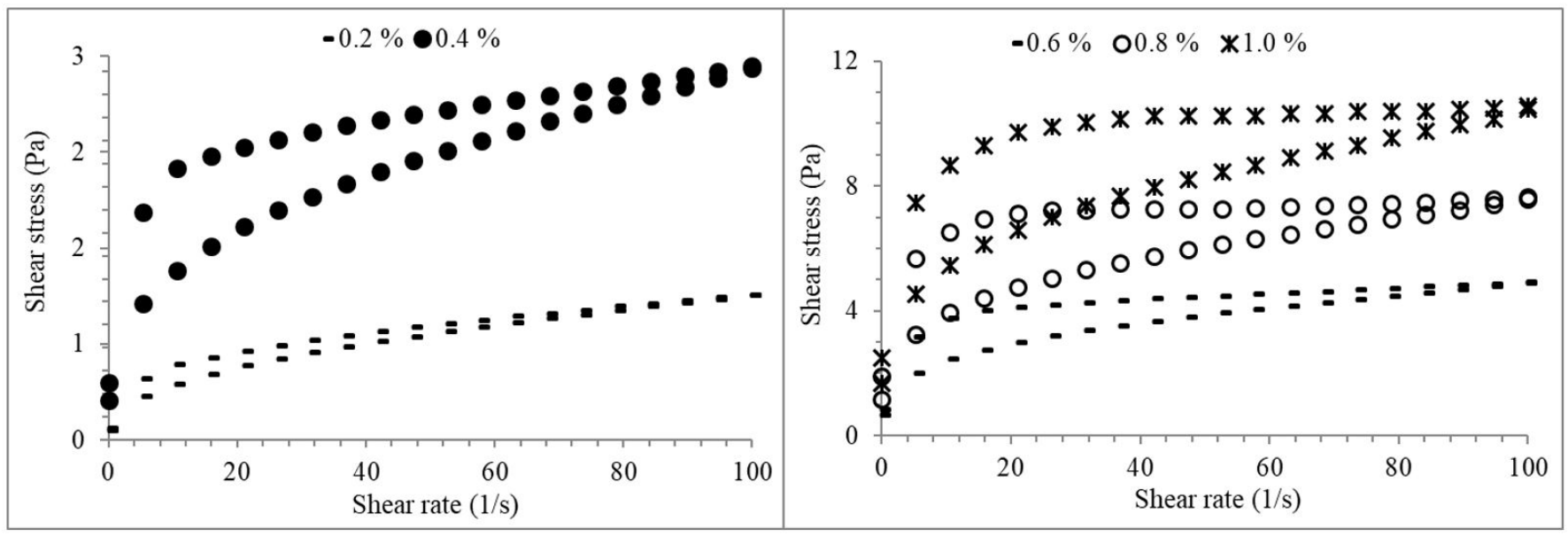

Figure 3. Time-dependent flow behavior of RSG solutions.

attention exceeded $0.4 \%$, the up and down curve much prominent and did not overlap, which indicated that the structure of RSG solutions changed by mechanical stress and energy loss. A similar result was obtained by other studies (Fathi et al., 2016; Wang et al., 2019). According to thixotropic properties of the RSG solutions, the RSG solutions can be used in the food industry due to having structural recovery properties.

\section{Three Interval Thixotropic Time Test (3-ITT)}

3-ITT is another method to describe the thixotropic properties of food emulsions and dispersions subjected to very high sudden deformation. In the first time interval, lower shear rates were applied to the RSG solutions at rest. A higher shear rate is applied to samples in the second time interval and caused structural decomposition of the RSG solutions. In the third time interval, the recovery of samples starts (Toker et al., 2015). In the food industry, applied deformations are not always within the linear viscoelastic region. The 3-ITT simulates sudden and nonlinear deformation of RSG solutions. Therefore, this test gives information about the structural recovery of RSG solutions.

As shown in Figure 4, the RSG solutions structural recovery tendency decreased with increasing concentrations of the RSG solutions. As we mentioned in the thixotropic properties of the RSG solutions, the lowest concentrations $(0.2 \%)$ demonstrated the lowest structural recovery. The highest concentrations (1\%) showed that the lowest structural recovery means that after deformation, it could not be returned to the original structure fast due to high viscosity and strength structural molecular interactions (Razmkhah et al., 2016; Wang et al., 2019).

Rheological data of the 3-ITT were fitted by the secondorder structural model to determine structural deformation and recovery ratio by using Equation 4 and Equation 5 and given in Table 3. $\mathrm{R}^{2}$ value higher than 0.94 , meaning that this model was successfully fitted to rheological data. The percentage of deformation for storage and loss modulus respectively ranged between $50.28 \%-70.27 \%, 26.80 \%-55.12 \%$ increased with increasing gum concentrations. Also, the percentage of recovery for storage and loss modulus, respectively ranged between $81.2 \%-42 \%$ and
$104 \%-55 \%$ decreased with increasing concentrations of the RSG. These results indicated that minimum and maximum recovery and deformation were obtained at $1 \%$ and $0.2 \%$ concentration of the RSG solutions for storage and loss modulus, respectively.

Also, $\mathrm{k}^{\prime}$ and $\mathrm{k}^{\prime \prime}$ values known as thixotropic values were found from 9.3-12.85 and 7.82-13.64 1/s, respectively, and decreased with increasing gum concentrations. Higher thixotropic rate values meaning a higher tendency to structural recovery (Akcicek \& Karasu, 2018). According to the results, $0.2 \%$ concentrations of the RSG solutions' concentrations higher tend to recover than the other concentrations. These results indicated that RSG solutions could be used in the food industry due to providing structural recovery advantages during food process conditions like pumping and filling (Wang et al., 2019).

\subsection{Dynamic shear properties}

Figure 5 showed the viscoelastic behavior of the RSG solutions. $G^{\prime}$ and $G^{\prime \prime}$ values of the samples at all concentrations increased with the increase of angular velocity. Similar behavior was reported for locust bean gum (Dakia et al., 2008) Hymenaea courbaril L. gum seed (Hernández-Morales et al., 2018). Figure 5 demonstrated that the RSG solutions at all concentrations $G^{\prime}$ were higher than $G^{\prime \prime}$ indicating that RSG showed solid viscoelastic character like gel behavior with all in frequency ranges.

A solid viscoelastic character is the desired rheological behavior for gum solutions. Such results are compatible with other hydrocolloids like L. perfoliatum seed gum gel (Hesarinejad et al., 2014), purified basil seed gum (Farahmandfar et al., 2019), cress seed gum (Razmkhah et al., 2017) basil seed gum (Rafe et al., 2012) Chinese quince seed gum (Wang et al., 2019), and A.homolacarpum seed gum (Anvari et al., 2016). An increase in concentrations of the RSG solutions led to an increase in $\mathrm{G}^{\prime}$ and $\mathrm{G}^{\prime \prime}$ (Table 4).

A similar result (Farahmandfar et al., 2019; NajiTabasi \& Razavi, 2017). This increase could be explained by the formation of a complex molecular structure at higher RSG concentrations (Hesarinejad et al., 2014). The rise in $\mathrm{G}^{\prime}$ and $\mathrm{G}^{\prime \prime}$ with an increase in concentrations of the RSG solutions can be 


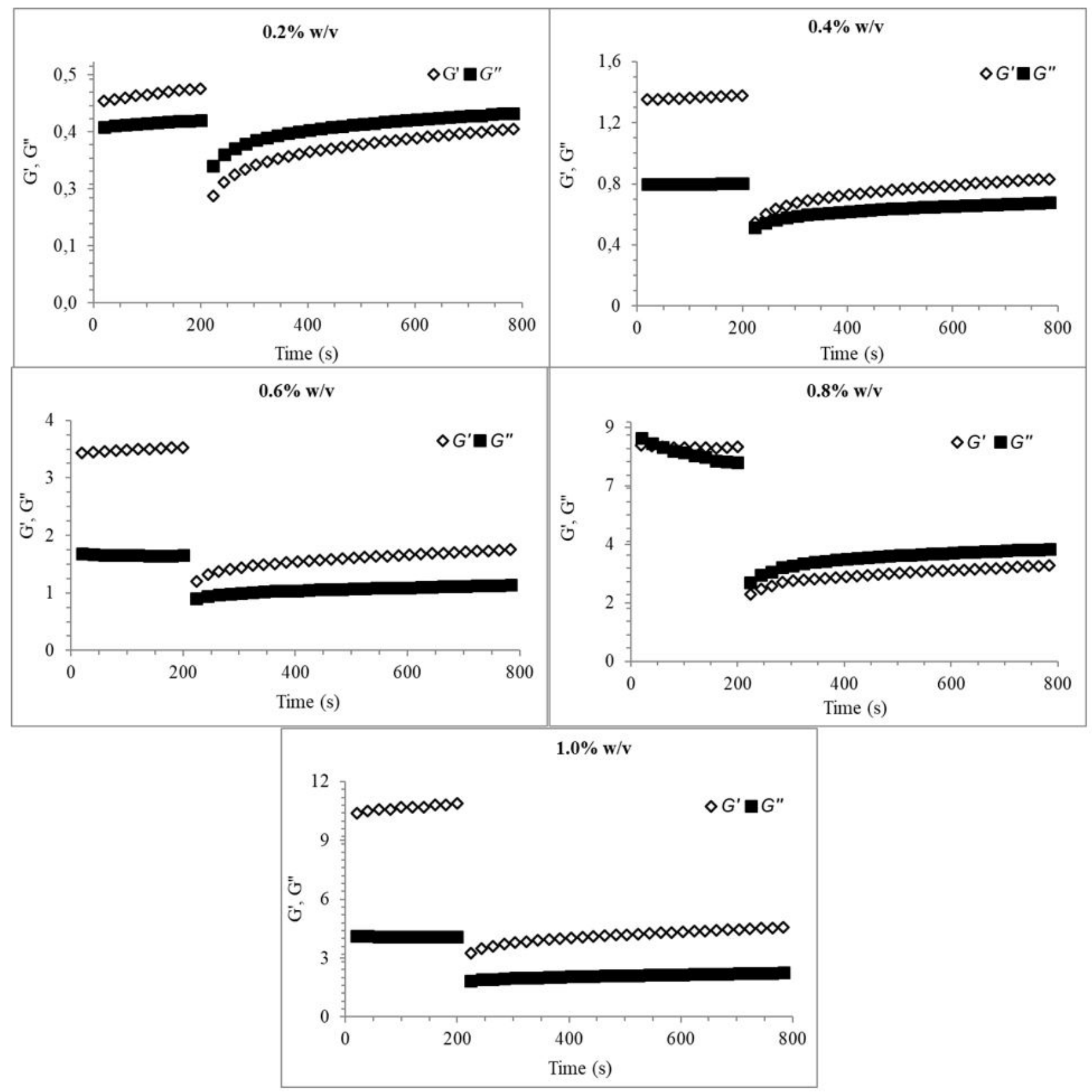

Figure 4. 3-ITT rheological properties of RSG solutions.

Table 3. Second-order structural model parameters

\begin{tabular}{|c|c|c|c|c|c|c|c|c|}
\hline \multirow{2}{*}{ Concentration (\%) } & \multicolumn{2}{|c|}{$\mathrm{G}^{\prime}$} & \multicolumn{2}{|c|}{$\mathrm{G}^{\prime \prime}$} & \multicolumn{2}{|c|}{ The percentage of Deformation } & \multicolumn{2}{|c|}{ The percentage of Recovery } \\
\hline & $\mathrm{R}$ & $\mathrm{k}\left(\mathrm{s}^{-1}\right)$ & $\mathrm{R}$ & $\mathrm{k}\left(\mathrm{s}^{-1}\right) \times 1000$ & $\mathrm{G}^{\prime}$ & $\mathrm{G}^{\prime \prime}$ & $\mathrm{G}_{\mathrm{e}} / \mathrm{G}_{0}$ & $\mathrm{G}_{\mathrm{e}} / \mathrm{G}_{0}$ \\
\hline 0.2 & 0.974 & $12.850^{\mathrm{a}}$ & 0.9761 & $13.642^{\mathrm{a}}$ & $50.28^{\mathrm{e}}$ & $26.80^{\mathrm{e}}$ & $81.205^{\mathrm{a}}$ & $104.101^{\mathrm{a}}$ \\
\hline 0.4 & 0.973 & $11.910^{\mathrm{b}}$ & 0.9493 & $11.602^{\mathrm{b}}$ & $62.63^{\mathrm{d}}$ & $40.77^{\mathrm{d}}$ & $66.386^{\mathrm{b}}$ & $89.353^{\mathrm{b}}$ \\
\hline 0.6 & 0.971 & $11.499^{c}$ & 0.9655 & $10.697^{\mathrm{c}}$ & $63.87^{\mathrm{c}}$ & $43.55^{\mathrm{c}}$ & $49.953^{\mathrm{c}}$ & $68.801^{\mathrm{c}}$ \\
\hline 0.8 & 0.967 & $10.090^{\mathrm{d}}$ & 0.9627 & $9.949^{d}$ & $65.24^{\mathrm{b}}$ & $48.63^{\mathrm{b}}$ & $46.061^{\mathrm{d}}$ & $60.487^{\mathrm{d}}$ \\
\hline 1.0 & 0.968 & $9.300^{\mathrm{e}}$ & 0.9573 & $7.822^{\mathrm{e}}$ & $70.27^{\mathrm{a}}$ & $55.12^{\mathrm{a}}$ & $42.540^{\mathrm{e}}$ & $55.054^{\mathrm{e}}$ \\
\hline
\end{tabular}

${ }^{\star}$ Different letters in the same column indicate significant differences among samples $(\mathrm{P}<0.05)$. 


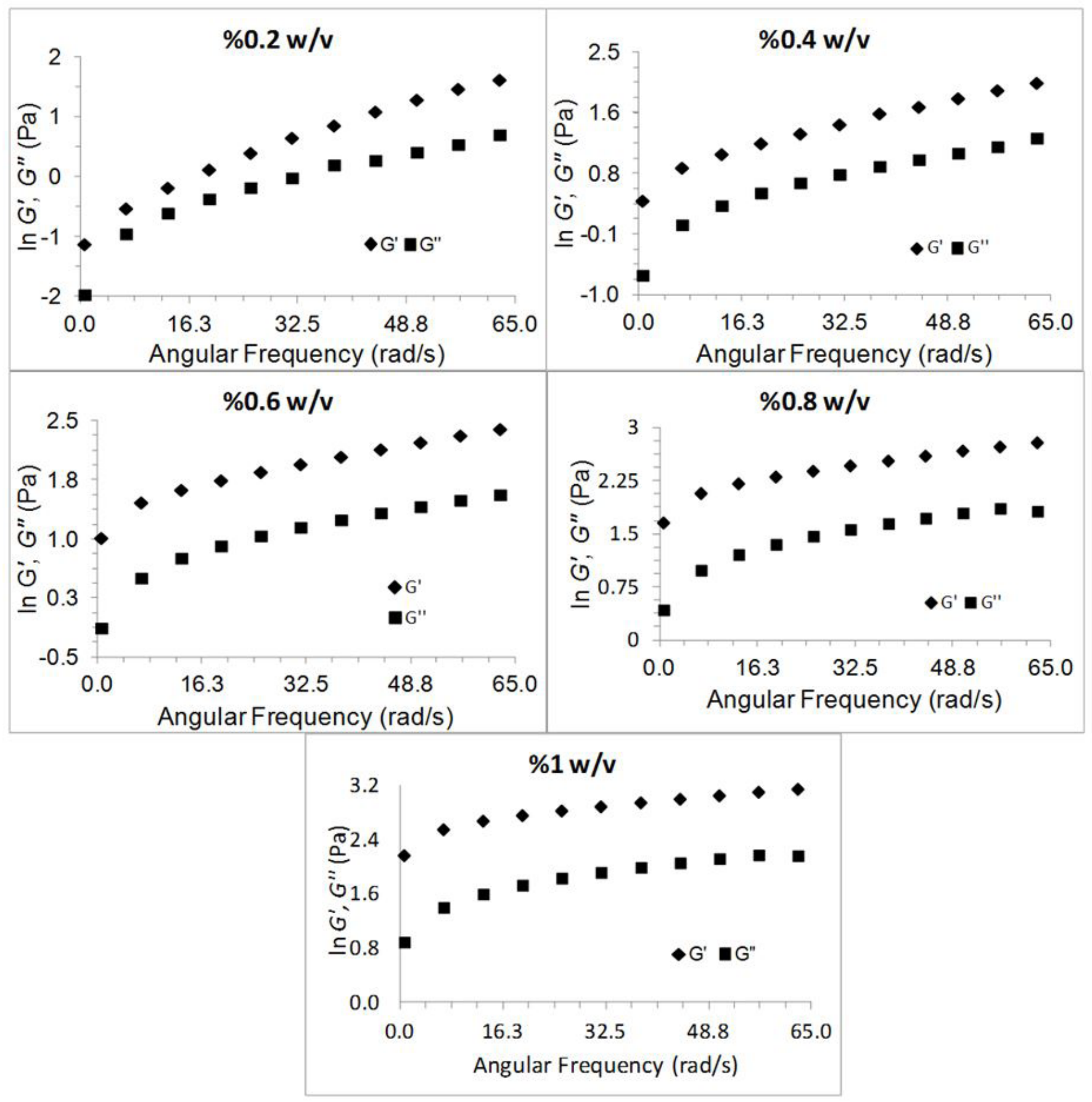

Figure 5. Dynamic rheological properties of RSG solutions.

explained by intermolecular networks between RSG and water molecules (Farahmandfar et al., 2019). A low concentration of RSG solution $(0.2 \%)$ also had elastic behavior. The reasons could be the high molecular weight and high branching degree of RSG (Wang et al., 2019).

Non-linear regression analyses were applied to data which is obtained from the frequency sweep test to calculate $K^{\prime}, K^{\prime \prime}, n^{\prime}$, $\mathrm{n}$ ", and $\mathrm{R}^{2} . \mathrm{R}^{2}$ was found to be higher than 0.95 , which means that the Power Law model was fitted and compatible with our finding results. At all concentration levels, $\mathrm{K}^{\prime}$ (0.03-8.22) values were higher than the $\mathrm{K}^{\prime \prime}(0.11-2.15)$ values. These results indicated that the solid character index of the samples was higher than the liquid character index. It means that all of the samples show solid viscoelastic behavior at all concentrations of the RSG solutions. $n$ ' and n" values of the samples indicating the nature and elastic properties of the gels. Besides, $n^{\prime}=0$ means that a covalent gel while n' $>0$ for a physical gel. A higher n' value means that the RSG solutions act a viscous gel while $n$ ' and $n$ " value near to zero means that $G$ ' and $G$ " don't change with frequency (Balaghi et al., 2011). 
Table 4. Parameters of Power-Law function describing of storage, loss modulus, and complex viscosity

\begin{tabular}{|c|c|c|c|c|c|c|c|c|c|}
\hline \multirow{2}{*}{ Concentration (\%) } & \multicolumn{3}{|c|}{$\mathrm{G}^{\prime}=\mathrm{K}^{\prime}(\omega)^{\mathrm{n}}$} & \multicolumn{3}{|c|}{$G^{\prime \prime}=K^{\prime \prime}(\omega)^{n "}$} & \multicolumn{3}{|c|}{$\eta^{*}=\mathrm{K}>(\omega)^{\mathrm{n}^{\prime}}-1$} \\
\hline & $\mathrm{K}^{\prime}(\mathrm{Pa})$ & n' & $\mathrm{R}^{2}$ & $\mathrm{~K}^{\prime \prime}(\mathrm{Pa})$ & n" & $\mathrm{R}^{2}$ & $\mathrm{~K}^{\star}(\mathrm{Pa})$ & $\mathrm{n}^{\star}$ & $\mathrm{R}^{2}$ \\
\hline 0.2 & $0.030^{\mathrm{e}}$ & $0.929^{a}$ & 0.990 & $0.115^{\mathrm{e}}$ & $0.630^{\mathrm{a}}$ & 0.955 & $0.049^{\mathrm{e}}$ & $1.122^{\mathrm{a}}$ & 0.990 \\
\hline 0.4 & $0.517^{\mathrm{d}}$ & $0.636^{\mathrm{b}}$ & 0.973 & $0.386^{\mathrm{d}}$ & $0.494^{\mathrm{b}}$ & 0.983 & $0.628^{\mathrm{d}}$ & $0.791^{\mathrm{b}}$ & 0.979 \\
\hline 0.6 & $1.715^{\mathrm{c}}$ & $0.426^{c}$ & 0.970 & $0.717^{\mathrm{c}}$ & $0.433^{\mathrm{c}}$ & 0.988 & $1.850 \mathrm{c}$ & $0.606^{c}$ & 0.980 \\
\hline 0.8 & $4.330^{\mathrm{b}}$ & $0.304^{\mathrm{d}}$ & 0.975 & $1.292^{\mathrm{b}}$ & $0.385^{\mathrm{d}}$ & 0.990 & $4.489^{\mathrm{b}}$ & $0.470^{\mathrm{d}}$ & 0.979 \\
\hline 1.0 & $8.224^{\mathrm{a}}$ & $0.249^{\mathrm{e}}$ & 0.982 & $2.159^{\mathrm{a}}$ & $0.346^{\mathrm{e}}$ & 0.992 & $8.460^{\mathrm{a}}$ & $0.320^{\mathrm{e}}$ & 0.984 \\
\hline
\end{tabular}

${ }^{*}$ Different letters in the same column indicate significant differences among samples $(\mathrm{P}<0.05)$

All of the RSG solutions showed gel-like due to the positive slopes ( $n$ were positive $\left(n^{\prime}=0.24-0.92\right.$ and $\left.n "=0.34-0.63\right)$. According to the information above, the lowest n' value (0.24) obtained at $1 \%$ concentration of the RSG solutions (Table 4 ) indicates that the result of storage modulus is displayed to create a more stable gel than the other concentrations of the RSG solutions. Besides, $0.2 \%$ concentrations of the RSG solutions showed the lowest $\mathrm{G}^{\prime}$, and G" means that ability to create an intertwined network is a weakness. In contrast, $1 \%$ concentration of the RSG solutions showed the highest $\mathrm{G}^{\prime}$ is related to form stronger, more elastic network structure and molecular interactions. A similar result was obtained by (Naji-Tabasi \& Razavi, 2017; Razmkhah et al., 2016).

The increase in frequency led to decreased complex viscosity of the RSG solutions. Therefore it can be indicated that dispersions of hydrocolloid exhibited Non-newtonian behavior with pseudo-plastic character. A similar result was obtained by (Rafe et al., 2013; Razmkhah et al., 2016). Nonlinear regression analyses were applied to data, and $\mathrm{K}^{*}$ and $\mathrm{n}^{\star}$ value $\left(\mathrm{R}^{2}=0.97\right)$ were found between 0.04-8.46 and 0.32-1.12, respectively (Table 4). Besides, increasing concentrations of the RSG caused an increase in complex viscosity (Table 4). At high frequency, the applied time of frequency was not sufficient for the destruction of the inter and intramolecular bonds. After the rearrangement of the molecule, therefore complex viscosity of the RSG solutions decreased. These results showed that RSG solutions could be utilized as a good stabilizer and thickener in the food industry (Hesarinejad et al., 2014).

\section{Conclusion}

In conclusion, RSG had high carbohydrate (80.38\%) and low protein $(5.81 \%)$ contents. Sugar analysis results showed that RSG was rich in mannose and galactose level. The mannose/ galactose ratio of the RSG (1.52) indicated that galactose's substitution level in gum polymers was very high. The higher level of galactose substitution exhibited higher solubility in water. FTIR spectrum of $1 \%$ RSG solution indicated the existence of carboxyl, hydroxyl and glycoside bands. RSG solutions showed shear thinning, time-dependent, and viscoelastic characteristics at low concentration $(0.2 \%)$. 3-ITT test was applied to determine the recovery characteristic of RSG under sudden and high deformation. RSG showed recovery at all concentrations. This study suggested that RSG could be used in a variety of applications in the food industry as thickeners, emulsifiers, and gelling agents depending on its physicochemical and rheological characterization.

\section{References}

Akcicek, A., \& Karasu, S. (2018). Utilization of cold pressed chia seed oil waste in a low-fat salad dressing as natural fat replacer. Journal of Food Process Engineering, 41(5), e12694. http://dx.doi.org/10.1111/ jfpe.12694.

Anvari, M., Tabarsa, M., Cao, R., You, S., Joyner, H. S., Behnam, S., \& Rezaei, M. (2016). Compositional characterization and rheological properties of an anionic gum from Alyssum homolocarpum seeds. Food Hydrocolloids, 52, 766-773. http://dx.doi.org/10.1016/j. foodhyd.2015.07.030.

Balaghi, S., Mohammadifar, M. A., Zargaraan, A., Gavlighi, H. A., \& Mohammadi, M. (2011). Compositional analysis and rheological characterization of gum tragacanth exudates from six species of Iranian Astragalus. Food Hydrocolloids, 25(7), 1775-1784. http:// dx.doi.org/10.1016/j.foodhyd.2011.04.003.

Balke, D. T., \& Diosady, L. L. (2000). Rapid aqueous extraction of mucilage from whole white mustard seed. Food Research International, 33(5), 347-356. http://dx.doi.org/10.1016/S0963-9969(00)00055-7.

Baur, F. J., \& Ensminger, L. G. (1977). The Association of Official Analytical Chemists (AOAC). Journal of the American Oil Chemists' Society, 54(4), 171-172. http://dx.doi.org/10.1007/BF02670789.

Bertuzzi, M. A., Slavutsky, A. M., \& Armada, M. (2012). Physicochemical characterisation of the hydrocolloid from Brea tree (Cercidium praecox). International Journal of Food Science \& Technology, 47(4), 768-775. http://dx.doi.org/10.1111/j.1365-2621.2011.02907.x.

Bhushette, P. R., \& Annapure, U. S. (2017). Comparative study of Acacia nilotica exudate gum and acacia gum. International Journal of Biological Macromolecules, 102, 266-271. http://dx.doi.org/10.1016/j. ijbiomac.2017.03.178. PMid:28390831.

Bhushette, P. R., \& Annapure, U. S. (2018). Physicochemical, functional and rheological investigation of Soymida febrifuga exudate gum. International Journal of Biological Macromolecules, 111, 1116-1123. http://dx.doi.org/10.1016/j.ijbiomac.2018.01.117. PMid:29366895.

Brummer, Y., Cui, W., \& Wang, Q. (2003). Extraction, purification and physicochemical characterization of fenugreek gum. Food Hydrocolloids, 17(3), 229-236. http://dx.doi.org/10.1016/S0268005X(02)00054-1.

Busch, V. M., Kolender, A. A., Santagapita, P. R., \& Buera, M. P. (2015). Vinal gum, a galactomannan from Prosopis ruscifolia seeds: Physicochemical characterization. Food Hydrocolloids, 51, 495-502. http://dx.doi.org/10.1016/j.foodhyd.2015.04.035.

Cui, W., Eskin, N. A. M., \& Biliaderis, C. G. (1993). Chemical and physical properties of yellow mustard (Sinapis alba L.) mucilage. Food Chemistry, 46(2), 169-176. http://dx.doi.org/10.1016/03088146(93)90032-B.

Cui, W., Mazza, G., Oomah, B. D., \& Biliaderis, C. G. (1994). Optimization of an Aqueous Extraction Process for Flaxseed Gum by Response 
Surface Methodology. Lebensmittel-Wissenschaft + Technologie, 27(4), 363-369. http://dx.doi.org/10.1006/fstl.1994.1074.

Dabestani, M., Kadkhodaee, R., Phillips, G. O., \& Abbasi, S. (2018). Persian gum: A comprehensive review on its physicochemical and functional properties. Food Hydrocolloids, 78, 92-99. http://dx.doi. org/10.1016/j.foodhyd.2017.06.006.

Dakia, P., Blecker, C., Robert, C., Wathelet, B., \& Paquot, M. (2008). Composition and physicochemical properties of locust bean gum extracted from whole seeds by acid or water dehulling pre-treatment. Food Hydrocolloids, 22(5), 807-818. http://dx.doi.org/10.1016/j. foodhyd.2007.03.007.

Daoub, R. M. A., Elmubarak, A. H., Misran, M., Hassan, E. A., \& Osman, M. E. (2018). Characterization and functional properties of some natural Acacia gums. Journal of the Saudi Society of Agricultural Sciences, 17(3), 241-249. http://dx.doi.org/10.1016/j.jssas.2016.05.002.

Dickinson, E. (2003). Hydrocolloids at interfaces and the influence on the properties of dispersed systems. Food Hydrocolloids, 17(1), 25-39. http://dx.doi.org/10.1016/S0268-005X(01)00120-5.

Eddy, N., Abechi, S., Ameh, P., \& Ebenso, E. (2013). GCMS, FTIR, SEM, physiochemical and rheological studies on Albizia zygia gum. Walailak Journal of Science and Technology, 10, 247-265. http:// dx.doi.org/10.2004/wjst.v10i3.295.

Farahmandfar, R., Salahi, M. R., \& Asnaashari, M. (2019). Flow behavior, thixotropy, and dynamic viscoelasticity of ethanolic purified basil (Ocimum bacilicum L.) seed gum solutions during thermal treatment. Food Science \& Nutrition, 7(5), 1623-1633. http://dx.doi.org/10.1002/ fsn3.992. PMid:31139375.

Fathi, M., Mohebbi, M., \& Koocheki, A. (2016). Introducing Prunus cerasus gum exudates: Chemical structure, molecular weight, and rheological properties. Food Hydrocolloids, 61, 946-955. http:// dx.doi.org/10.1016/j.foodhyd.2016.07.004.

Fijan, R., Šostar-Turk, S., \& Lapasin, R. (2007). Rheological study of interactions between non-ionic surfactants and polysaccharide thickeners used in textile printing. Carbohydrate Polymers, 68(4), 708-717. http://dx.doi.org/10.1016/j.carbpol.2006.08.006.

Gadkari, P. V., Tu, S., Chiyarda, K., Reaney, M. J. T., \& Ghosh, S. (2018). Rheological characterization of fenugreek gum and comparison with other galactomannans. International Journal of Biological Macromolecules, 119, 486-495. http://dx.doi.org/10.1016/j. ijbiomac.2018.07.108. PMid:30031082.

Hamidabadi Sherahi, M., Fathi, M., Zhandari, F., Hashemi, S. M. B., \& Rashidi, A. (2017). Structural characterization and physicochemical properties of Descurainia sophia seed gum. Food Hydrocolloids, 66, 82-89. http://dx.doi.org/10.1016/j.foodhyd.2016.12.010.

Hernández-Morales, M. Á., Maldonado-Astudillo, Y. I., JiménezHernández, J., Salazar, R., Ramírez-Sucre, M. O., Ibarz, A., UtrillaCoello, R. G., \& Ortuño-Pineda, C. (2018). Physicochemical and rheological properties of gum seed and pulp from Hymenaea courbaril L. CYTA: Journal of Food, 16(1), 986-994. http://dx.doi. org/10.1080/19476337.2018.1513955.

Hesarinejad, M. A., Koocheki, A., \& Razavi, S. M. A. (2014). Dynamic rheological properties of Lepidium perfoliatum seed gum: Effect of concentration, temperature and heating/cooling rate. Food Hydrocolloids, 35, 583-589. http://dx.doi.org/10.1016/j.foodhyd.2013.07.017.

Jahanbin, K., Moini, S., Gohari, A. R., Emam-Djomeh, Z., \& Masi, P. (2012). Isolation, purification and characterization of a new gum from Acanthophyllum bracteatum roots. Food Hydrocolloids, 27(1), 14-21. http://dx.doi.org/10.1016/j.foodhyd.2011.09.007.

Kačuráková, M., Belton, P. S., Wilson, R. H., Hirsch, J., \& Ebringerová, A. (1998). Hydration properties of xylan-type structures: an FTIR study of xylooligosaccharides. Journal of the Science of Food and Agriculture, 77(1), 38-44. http://dx.doi.org/10.1002/(SICI)10970010(199805)77:1<38::AID-JSFA999>3.0.CO;2-5.

Karazhiyan, H., Razavi, S. M. A., Phillips, G. O., Fang, Y., Al-Assaf, S., Nishinari, K., \& Farhoosh, R. (2009). Rheological properties of Lepidium sativum seed extract as a function of concentration, temperature and time. Food Hydrocolloids, 23(8), 2062-2068. http:// dx.doi.org/10.1016/j.foodhyd.2009.03.019.

Koocheki, A., Razavi, S., \& Hesarinejad, M. A. (2011). Effect of Extraction Procedures on Functional Properties of Eruca sativa Seed Mucilage. Food Biophysics, 7. http://dx.doi.org/10.1007/s11483-011-9245-9.

Koocheki, A., \& Razavi, S. M. A. (2009). Effect of concentration and temperature on flow properties of alyssum homolocarpum seed gum solutions: assessment of time dependency and Thixotropy. Food Biophysics, 4(4), 353-364. http://dx.doi.org/10.1007/s11483009-9134-7.

Koocheki, A., Razavi, S. M. A., \& Hesarinejad, M. A. (2012). Effect of Extraction Procedures on Functional Properties of Eruca sativa Seed Mucilage. Food Biophysics, 7(1), 84-92. http://dx.doi.org/10.1007/ s11483-011-9245-9.

Koocheki, A., Taherian, A. R., \& Bostan, A. (2013). Studies on the steady shear flow behavior and functional properties of Lepidium perfoliatum seed gum. Food Research International, 50(1), 446-456. http://dx.doi.org/10.1016/j.foodres.2011.05.002.

Koubaa, M., Mhemdi, H., Sanlaville, Q., \& Vorobiev, E. (2016). Recovery of Oil, Erucic Acid, and Phenolic Compounds from Rapeseed and Rocket Seeds. Chemical Engineering \& Technology, 39(8), 1431-1437. http://dx.doi.org/10.1002/ceat.201500444.

Lee, C. H., Moturi, V., \& Lee, Y. (2009). Thixotropic property in pharmaceutical formulations. Journal of Controlled Release, 136(2), 88-98. http://dx.doi.org/10.1016/j.jconrel.2009.02.013. PMid:19250955.

Maskan, M., \& Gögüş, F. (2000). Effect of sugar on the rheological properties of sunflower oil-water emulsions. Journal of Food Engineering, 43(3), 173-177. http://dx.doi.org/10.1016/S0260-8774(99)00147-8.

Miyazawa, M., Maehara, T., \& Kurose, K. (2002). Composition of the essential oil from the leaves of Eruca sativa. Flavour and Fragrance Journal, 17(3), 187-190. http://dx.doi.org/10.1002/ffj.1079.

Nail, T., Ali, M., \& Salim, E. (2017). Phytochemical studies on Sudanese rocket (Eruca sativa) seeds and oil constituents. Am J Phytomed Clinic Therapeut, 5(1), 1-5.

Naji-Tabasi, S., \& Razavi, S. M. A. (2017). New studies on basil (Ocimum bacilicum L.) seed gum: Part III - Steady and dynamic shear rheology. Food Hydrocolloids, 67, 243-250. http://dx.doi. org/10.1016/j.foodhyd.2015.12.020.

Perry, L. M., \& Metzger, J. (1980). Medicinal plants of East and Southeast Asia: attributed properties and uses. Cambridge, Massachusetts: MIT Press.

Rafe, A., Razavi, S., \& Farhoosh, R. (2013). Rheology and microstructure of basil seed gum and? -lactoglobulin mixed gels. Food Hydrocolloids, 30(1), 134-142. http://dx.doi.org/10.1016/j.foodhyd.2012.05.016.

Rafe, A., Razavi, S. M. A., \& Khan, S. (2012). Rheological and structural properties of $\beta$-lactoglobulin and basil seed gum mixture: Effect of heating rate. Food Research International, 49(1), 32-38. http://dx.doi. org/10.1016/j.foodres.2012.07.017.

Razavi, S. M. A., Cui, S. W., Guo, Q., \& Ding, H. (2014). Some physicochemical properties of sage (Salvia macrosiphon) seed gum. Food Hydrocolloids, 35, 453-462. http://dx.doi.org/10.1016/j. foodhyd.2013.06.022.

Razmkhah, S., Razavi, S. M. A., \& Mohammadifar, M. A. (2016). Purification of cress seed (Lepidium sativum) gum: A comprehensive 
rheological study. Food Hydrocolloids, 61, 358-368. http://dx.doi. org/10.1016/j.foodhyd.2016.05.035.

Razmkhah, S., Razavi, S. M. A., \& Mohammadifar, M. A. (2017). Dilute solution, flow behavior, thixotropy and viscoelastic characterization of cress seed (Lepidium sativum) gum fractions. Food Hydrocolloids, 63, 404-413. http://dx.doi.org/10.1016/j.foodhyd.2016.09.030.

Saeidy, S., Nasirpour, A., Djelveh, G., Ursu, A.-V., Delattre, C., Pierre, G., \& Michaud, P. (2019). Emulsion properties of Asafoetida gum: Effect of oil concentration on stability and rheological properties. Colloids and Surfaces. A, Physicochemical and Engineering Aspects, 560, 114-121. http://dx.doi.org/10.1016/j.colsurfa.2018.10.018.

Singthong, J., Ningsanond, S., Cui, S. W., \& Douglas Goff, H. (2005). Extraction and physicochemical characterization of Krueo Ma Noy pectin. Food Hydrocolloids, 19(5), 793-801. http://dx.doi.org/10.1016/j. foodhyd.2004.09.007.

Tada, T., Matsumoto, T., \& Masuda, T. (1998). Structure of molecular association of curdlan at dilute regime in alkaline aqueous systems. Chemical Physics, 228(1), 157-166. http://dx.doi.org/10.1016/S03010104(97)00343-1.

Toker, O. S., Karasu, S., Yilmaz, M. T., \& Karaman, S. (2015). Three interval thixotropy test (3ITT) in food applications: A novel technique to determine structural regeneration of mayonnaise under different shear conditions. Food Research International, 70, 125-133. http:// dx.doi.org/10.1016/j.foodres.2015.02.002.

Vardhanabhuti, B., \& Ikeda, S. (2006). Isolation and characterization of hydrocolloids from monoi (Cissampelos pareira) leaves.
Food Hydrocolloids, 20(6), 885-891. http://dx.doi.org/10.1016/j. foodhyd.2005.09.002.

Vinod, V. T. P., Sashidhar, R. B., Sarma, V. U. M., \& Vijaya Saradhi, U. V. R. (2008). Compositional Analysis and Rheological Properties of Gum Kondagogu (Cochlospermum gossypium): A Tree Gum from India. Journal of Agricultural and Food Chemistry, 56(6), 2199-2207. http://dx.doi.org/10.1021/jf072766p. PMid:18318494.

Wang, L., Liu, H.-M., Zhu, C.-Y., Xie, A.-J., Ma, B.-J., \& Zhang, P.-Z. (2019). Chinese quince seed gum: Flow behaviour, thixotropy and viscoelasticity. Carbohydrate Polymers, 209, 230-238. http://dx.doi. org/10.1016/j.carbpol.2018.12.101. PMid:30732804.

Wang, S., Tang, H., Guo, J., \& Wang, K. (2016). Effect of pH on the rheological properties of borate crosslinked hydroxypropyl guar gum hydrogel and hydroxypropyl guar gum. Carbohydrate Polymers, 147, 455-463. http://dx.doi.org/10.1016/j.carbpol.2016.04.029. PMid:27178952.

Yoo, B., \& Rao, M. A. (1996). Creep AND DYNAMIC RHEOLOGICAL BEHAVIOR OF TOMATO CONCENTRATES: EFFECT OF CONCENTRATION AND FINISHER SCREEN SIZE. Journal of Texture Studies, 27(4), 451-459. http://dx.doi.org/10.1111/j.1745-4603.1996. tb00087.x.

Zhong, L., Oostrom, M., Truex, M. J., Vermeul, V. R., \& Szecsody, J. E. (2013). Rheological behavior of xanthan gum solution related to shear thinning fluid delivery for subsurface remediation. Journal of Hazardous Materials, 244-245, 160-170. http://dx.doi.org/10.1016/j. jhazmat.2012.11.028. PMid:23246952. 